\title{
Correction to: Dedicated breast CT: state of the art-Part I. Historical evolution and technical aspects
}

\author{
Yueqiang Zhu ${ }^{1}$. Avice M. O'Connell ${ }^{2} \cdot$ Yue Ma ${ }^{1} \cdot$ Aidi Liu $^{1} \cdot$ Haijie Li ${ }^{1} \cdot$ Yuwei Zhang ${ }^{1} \cdot$ Xiaohua Zhang $^{3}$. \\ Zhaoxiang $\mathrm{Ye}^{1}{ }^{1}$
}

Published online: 7 January 2022

(c) The Author(s), under exclusive licence to European Society of Radiology 2021

\section{Correction to: European Radiology \\ https://doi.org/10.1007/s00330-021-08179-z}

The original version of this article, published on 03 August 2021, unfortunately contained a mistake. The citation order of the references 69 and 70 was incorrect. The original article has been corrected.

Publisher's note Springer Nature remains neutral with regard to jurisdictional claims in published maps and institutional affiliations.

The original article can be found online at https://doi.org/10.1007/ s00330-021-08179-z.

Zhaoxiang Ye

yezhaoxiang@163.com

1 Department of Radiology, Tianjin Medical University Cancer Institute and Hospital, National Clinical Research Center for Cancer, Key Laboratory of Cancer Prevention and Therapy, Tianjin, Tianjin's Clinical Research Center for Cancer, Key Laboratory of Breast Cancer Prevention and Therapy, Tianjin Medical University, Ministry of Education, Huan-Hu-Xi Road, Ti-Yuan-Bei, Hexi District, Tianjin 300060, China

2 Department of Imaging Sciences, University of Rochester Medical Center, 601 Elmwood Avenue, Box 648, Rochester, NY 14642, USA

3 Koning Corporation, Lennox Tech Enterprise Center, 150 Lucius Gordon Drive, Suite 112, West Henrietta, NY 14586, USA 